\title{
Assessment of Biocompatibility of Materials for Implantology on the Protein Level
}

\author{
Marianna Trebuňová * , Katarína Šromovská \\ Faculty of Mechanical Engineering, Department of Biomedical Engineering and Measurement, Technical University of Košice, Letná 9, 04200 Košice, \\ Slovakia
}

\begin{abstract}
Nowadays, the implants are used medically in various parts of human body, for example dental implants, cartilage replacements, joints, ties, tendons etc. Before the actual implantation, it is necessary to verify the safety and suitability of the implant use in that certain body part. That is done on the basis of the biocompatibility of the material used to produce the "artificial"replacement. The biocompatibility is basically the tolerance of different substances in biological environment. It is evaluated according to interactions between the given material and the organism (tissue), or between the environment, it is placed into. If the implant is incompatible with the organism, the organism will not adopt the implant, thus the implantation itself is not suitable. There are special materials called biomaterials these are able to work in conjunction with living organism and having minimum of adverse effects. The initial evaluations are ongoing on the cell- and protein levels.
\end{abstract}

Keywords: implants, biocompatibility, MTT test, Elisa test.

\section{Introduction}

The fibre engineering is a way of cultivating natural fibres in the laboratory to be later used for medical purposes in regenerative medicine. By this way, it is possible to repair or completely replace the damaged fibres in the body. For this purpose, the cells are taken from the patient, then artificially cultivated and implanted again. The advantage of it is that the body will not identify the cultivated fibre as a foreign object, therefore will not refuse it, as it often does by organ transplants. The case, when the donor and recipient is the same person, is called autologous transplantation.

For the purposes of fibre engineering, usually mainly differentiated cells, e.g. from cartilage fibre, were used until recent times. By this way, the blood vessel replacements and heart valves were cultivated. However, to achieve this goal, a, so called, structural carrier is necessary to provide and indicate the shape and is colonized by cells. These autologous blood vessel vaccinations cannot be used as a working artery system, if they cannot be replaced by their own body blood vessels. When talking about children, the main advantage of the fibre engineering is the "production" of prostheses which will grow together with the body, therefore there is no need to replace them for alternative plastic prostheses. The cultivation of skin fibres has established itself in regenerative medicine as well, and it is recently used for inflammations treatment.

Even though in the field of fibre engineering some promising results were already achieved, very intensive research still takes place in this field. These processes should always be improved and in the future used for treatment of diseases and injuries, with the lowest risk possible. Adult mesenchymal stem cells, as well as induced pluripotent stem cells are very interesting subject of fibre engineering, because they can be differentiated into various kinds of tissues. The scientists expect that in 
the future even the cultivation of functional organs in vitro will be performed by stem cell therapy, so that the transplants of donor organs can be eliminated in the highest merit possible. The fibre engineering has a big meaning even for a basic research, because artificially created fibres help the scientists to test the effects of pollutants or new drugs.

Alogenous transplantation, by which the donor and the recipients are two different people, is performed mainly by various types of leukaemia and lymphoma. When a suitable donor is found, the cells are gained by traditional collection from the bone marrow, or what is more preferred today, by collection from peripheral stem cells, in which these cells are filtrated from donor's blood. Use of stem cells taken from umbilical cord blood is also possible [1-4].

\section{Factors influencing the choice of the correct implant}

There are many factors influencing the biocompatibility of implants, for example size, shape, material composition, surface absorption, roughness and load. To evaluate the material biocompatibility, any harmful reactions that can rise on the interface of blood or fibre with material have to be minimal, whereas the resistance to biodegradation has to be high. Therefore, the biomaterial should behave as a natural material when interacting with blood and fibre. The materials used for implants should not:

- cause blood clots

-influence the blood plasma proteins (includ-ing enzymes), cause harmful reactions of immune system (inflammations)

- cause cancer

- cause taratologic effects, effect influencing the shapes

- cause toxic and allerigic reactions

- be influenced by sterilization.

Recently, there is no material known that would completely suit these criteria. Therefore, whenever a foreign material is placed into a biological environment, it is possible that the reactions harmful for host environment or for the material may rise. The biocompatibility can be described as multifactor. That means that different properties of material influence the host environment. The fibre reaction starts by inflammation at the implantation place. The nearer capillaries grow in diametric way (they extend) and cause the growth of cell permeability. This allows the liquid to flow into surrounding tissues and cause swellings. It was found that the change in blood flow on the implant side can be immediately connected to the size of the inflammation reaction. At the inflamed spot, the neutrophils appear first - these are a type of leukocytes responsible for phagocytosis. Accumulation of these and also other leukocytes activates the macrophages, which excrete the mediators of inflammation and fibre destruction. This leads to formation of big foreign body cells and fibroblasts, while both of them are the key factors of the inflammation process [5].

\section{Cell models for in vitro study of mezenchymal cells}

Recently, there are several companies supplying cells lines of different types. To evaluate the biocompatibility of implants, the mezenchymal cell lines are the most suitable candidates. These lines can be used in the field of fibre engineering and regenerative medicine for the studies of stem cells differentiations in adults and for creation of induced pluripotent stem cells. Commercial companies offer mezenchymal stem cells lines cultivated from various sources, e. g. from adipose tissue, bone marrow and from umbilical cord tissue. These lines are able to differentiate adipogenic, osteogenic and chondrogenic lines.

\section{Markers for study of biokompatibility of materials for implantology}

Atpresent, the research of material biocompatibility is based mainly on evaluating of proteins produced by osteoblasts and fibroblasts into intercellular mass [6-8].

\section{A) Proteins involved in inflammation process:}

Cytokine is a name for a group of smaller signal proteins taking significant place in immunity response (they provide the communication among white blood cells). Cytokines are produced by the immunity system cells (macrophages, T-lymphocytes) and are able to incite fast division and differentiation of certain types of cells that are fighting against pathogens, or other functions of immune defence. In a certain sense, cytokines do not have to be produced by white blood cells only, and meaning of the word is widened to all small signal proteins; the term interleukin is in that case used for signal molecules excreted by white blood 
cells.

Apart from this, also membrane forms of various cytokines can be found. These are, unlike secreted cytokine forms embedded in the cytoplasmic membrane, using hydrophobic sequences consisting of approximately 20 amino acids. As membrane cytokines we can consider also several signalling surface proteins (CD80, CD86, CD40L, FasL). Unlike the others, membrane cytokines have a significant local effect, are not diluted by diffusion and carried away [9].

Other groups of cytokines:

lymphokines - produced by lymphocytes, activated by macrophags,

interferons - defence against virus infections and regulation of immunity response,

colonies stimulating factors (CSF) - stimulate the growth and differentiation of certain white blood cells,

polypeptide growth factors - various factors, e. g. FGF, EGF or VEGF.

- FGF (fibroblast growth factor) - participates in angiogenesis, wound healing and embry-onic evolution. FGF are the key factors of proliferation processes and differentiation of a wide scale of cells and tissues.

- EGF (epidermal growth factor) - a protein containing 53 amino acids, belongs among mitogens (stimulants of cell division or mito-sis). Controls a great amount of various cell processes, stimulates cell division (proliferation) of many eukaryotic cells. EGF binds to its specific receptors at the cell surface, so called EGF receptors (EGFR).

- VEGF (vascular endothelial growth factor) - signal protein produced by cells stimulating the blood vessels creation. These are im-portant proteins participating in vasculogene-sis (process of new blood vessels creation) and by angiogenesis (growth of blood vessels from already existent blood vessels). transforming growth factors - regulating functions in embryonic evolution, in immunity system,

chemokines - they evoke migration (movement, chemotaxis) of certain cells,

stress proteins - response to negative conditions in cells' surroundings.

Tumour necrosis factor (TNF) is a group of cytokines (so, certain signal substances of immunity system). TNF is created mainly in white blood cells referred to as macrophags, most often as a reaction to bacterial or other infection, tumour growth etc. The creation of TNF is supported by the effects of interleukins. TNF is also able to cause the cell death of the tumour cells.

There are two basic types of TNF:

$\checkmark$ TNF-a (produced mostly by macrophags)

$\checkmark$ TNF- $\beta$ (so called lymphotoxine, produced by various T-lymphocytes) [9].

Interleukins are groups of cytokines taking part in immunity processes regulation. From the biochemical point of view, we are talking about several groups of proteins (e. g. interleukins of family IL-10 or IL-1) in Tab. 1.. Interleukins were named after it was found out that they are substances produced by leukocytes (white blood cells), regulating their mutual interactions. By other researches it was found out that interleukins are not produced by white blood cells only, but rather by various other kinds of cells (e. g. various epithelial cells). Various interleukins affect many cell types and their effects are mutually complementing and overlapping.

Some of the interleukins we can call according to the reactions they are causing, as inflammatory (e.g. IL-1, 2), or anti-inflammatory (buffering, e. g. IL-10) $[5,6,8,9]$.

Tab. 1: Interleukins involved in inflammation.

\begin{tabular}{|c|c|c|c|}
\hline Name & Source & Target cells & Function \\
\hline IL-1 & $\begin{array}{l}\text { macrophages, B- } \\
\text { lymphocytes, monocytes, } \\
\text { dendritic cells }\end{array}$ & $\begin{array}{l}\text { THB-lymphocytes, } \\
\text { NK cells, macrophages endothelium }\end{array}$ & $\begin{array}{l}\text { inflammation interleukin, small amounts } \\
\text { induce acute phase reaction }\end{array}$ \\
\hline IL-6 & $\begin{array}{l}\text { macrophages, TH2B- } \\
\text { lymphocytes, astrocytes, } \\
\text { endothelium }\end{array}$ & $\begin{array}{l}\text { activated B-lymphocytes, } \\
\text { plasma cells, T-cells, } \\
\text { bone marrow cells }\end{array}$ & $\begin{array}{l}\text { induces acute phase reaction, haematopoiesis, } \\
\text { differentiation, inflammation }\end{array}$ \\
\hline IL-7 & $\begin{array}{l}\text { bone marrow stromal cells and thymus stromal } \\
\text { cells }\end{array}$ & B-cells develop from bone marrow cells & $\begin{array}{l}\text { growth factor bone marrow cells, inflamma- } \\
\text { tory cytokine }\end{array}$ \\
\hline IL-8 & $\begin{array}{l}\text { macrophages, lymphocytes, } \\
\text { epitel cells, endotel }\end{array}$ & $\begin{array}{l}\text { neutrophils, basophils, } \\
\text { lymfocytes }\end{array}$ & neutrophil chemotaxis \\
\hline
\end{tabular}




\section{B) Markers involved in healing process:}

Collagen - Col - protein of intercellular mass, which is very important at the process of forming new connective fibres. Gingival fibroblasts and osteoblasts produce collagen I and III [6,8,10].

- Collagen I is one of the primary markers for osteoblasts. Its formation is increased by in-volvement of osteoprogenitors and at the same time it is stored in the intercellular mass by osteoblastic differentiation. It is a wellknown fact that collagen helps with fast bone regeneration and is also one of the main substances of gingival connecting tissue, while collagen III is important for fibre elastici-ty.

Alkaline phosphatase - ALP - glycoprotein, that belongs into the family of proteins anchored in the plasmatic membrane via the connection with glycosylphosphatidylinositol. It is rich in matrix vesicles that play an important role in the intercellular mass processes and by bone calcification. Therefore, it is commonly used as a biochemical marker of osteoblasts to evaluate the osteoblastic differentiation. The levels of ALP are increased in osteoblasts mainly before the bone mineralization, although the role of alkaline phosphatise during the mineralization is not well known yet. On the other side, high levels of this protein present in a wound signal the inflammation $[6,8,11]$.

Tenaskin - TN - glycoprotein of intercellular mass, expression of which is regulated by growth factors, including transforming growth factor beta TGF- $\beta$, and by mechanical stress $[6,8,12]$. It is expressed during the wound healing process, nerves regeneration, tissues involution and by pathological states including vascular diseases and the formation of tumours [13]. In dental fibres it is involved into the odontoblast differentiation forming the inner surface of a tooth $[6,8,14]$.

Fibronectine-FN-heterodimericadhesiveglycoprotein that consists of two subunits [15]. It is expressed by epithelial, endothelial and mesenchymal cells. The soluble form of fibronectine circulates in blood and other body liquids. The insoluble forms are accumulated at the cell surface and are kept in the intercellular mass [16]. Fibronectine is involved in adhesion, migration, growth and differentiation of cells. It also plays a significant role in keeping the fibre healthy, because it conveys the interactions between the cell and the intercellular mass $[6,8,14]$.

Osteonectine and osteopontine - adhesive glycoproteins that are localized in mineralized intercellular mass of a bone $[6,8,17]$. These proteins are primarily synthesized by osteoblasts, endothelial cells and megakaryocytes. They are responsible for bone mineralization regulation, because they help to store the calcium phosphate, and they inhibit the growth of hydroxyapatite crystals $[6,8,18]$.

Laminine-5(LM-5) - plays an important role at formation of hemidesmozomes that are present in contact fields of some epithelia with their basal membrane. Hemidesmozomes convey the grip of epithelia cells to variety of natural substances including dental enamel or to implantation materials, such as titan and ceramics. Epithelial cells adhere simpler to LM-5 than to other elements of intercellular mass, such as laminine-1, laminine- 2 and fibronectine. Tight cell connection by hemidesmozones to LM- 5 leads to successful long-term stability of dental implant $[6,8,19]$.

Bone sialoproteine (BSP) - forms approximately 15\% of non-collagen bone proteins. It is expressed by several types of cells that are involved into the fibre mineralization. It is mostly produced by osteoblasts. BSP contains shape segmented areas able to join several substances of intercellular mass with various biological function including collagen, matrix metaloproteinases, but in the same merit also integrines. In vitro experiments with osteoblasts and bone marrow cells showed that bone sialoproteine does not stimulate only the newly formed organic mass calcification, but also helps the cellular proliferation and expression of osteoblastic phenotypes. It turns out that it could be involved in the differentiation of osteoblasts and in the first phase of mineralization $[6,8,20,21]$.

Adhesive proteins - in the cellular regulation, differentiation and cell survival, cell adhesion to intercellular mass has a very significant meaning. Stabilization of the implanted material requires strong cell adhesion to its surface. That is dependent mostly on the signal conveyed by focal adhesion. Focal adhesion is a complex formed by cytoskeletal proteins, such as vinculine, taline, actinine, F-actine and paxilline. Actine fibres are joined together by these proteins with transmembrane integrine receptors and intercellular mass. By this joint, tight adhesion of cells to the dental material is guaranteed $[5,6,8,22,23]$.

\section{Possibilities of evaluation of biokompatibility at protein level}

Cultivation of cell lines will be performed according to instructions provided by supplier of cell line. 
MTT test: It is a colometric test performed to evaluate the cell metabolic activity, for the evaluation of cell vitality, to measure the cytotoxicity (loss/ destruction of vital cells), and also the cytostatic activity is measured. Yellow MTT (yellow tetrazolium) 3-(4,5-dimethylthiazol-2-yl)-2,5-diphenyltetrazolium - that is soluble in water, is reduced by mitochondrial enzymes to formazan derivate of purple colour that will stay inside the cells in its insoluble form. This insoluble formazan can solubilise by the use of isopropanol or other dissolvent. Subsequently, the solubilised material is measured by spectrophotometer, by which the absorbance as a function of concentration of transformed dye is gained. The presence of vital cells is detected as an active mitochondrial dehydrogenase of vital cells causing this conversion. Dead cells do not produce dehydrogenase therefore they will not cause the change. The amount of formazan production is directly proportional to the number of vital cells in the sample. Everything is performed according to supplier's instructions (Fig. 1) [24].

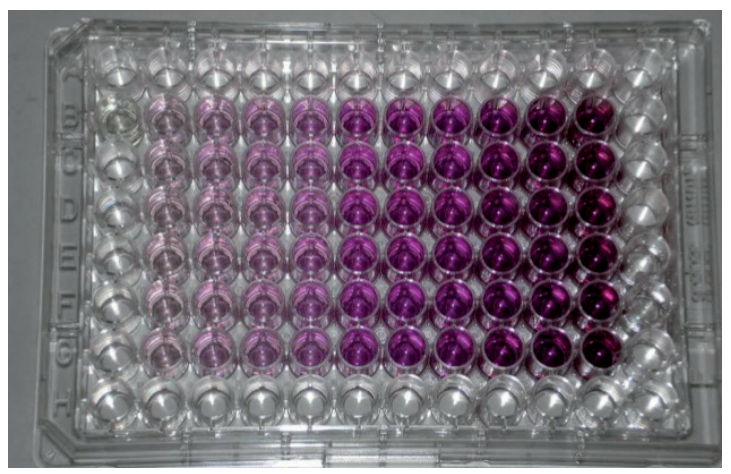

Fig. 1: Plate after release of formazan from the cells. The darkest purple color reflects the highest concentration of cells.

ELISA test (Enzyme-Linked ImmunoSorbent Assay), sometimesalsoknownas EIA(Enzymelmmunoassay) is one of the most often used immunological methods to detect the antibodies. This method works on the basis of immunoenzymatic reaction and by use of this method it is also possible to detect the antigen. ELISA uses two main characteristics of immunoglobulines. First, it is the ability of proteins (immunoglobulines) to connect to plastic surfaces (e. g. Polystyrene) and secondly, its ability to bound enzymes to Fc fragments of immunoglobuline molecules (Fig. 2) [25, 26].

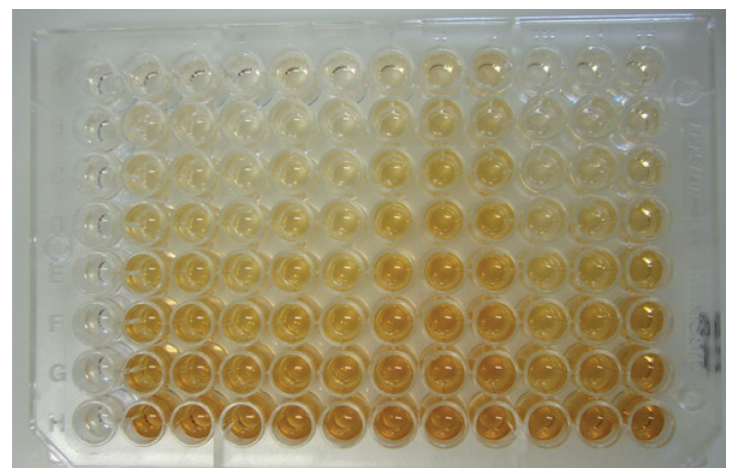

Fig. 2: A 96-well microtiter plate being used for ELISA.

\section{Conclusions}

The assessment of biocompatibility of materials, from which the implants are to be produced, is the necessary step when talking about its development. At first, the biocompatibility on the cellular and molecular (protein and DNA) levels is evaluated, later it is on the animal level and only after these steps the assessment is performed on the level of humans.

\section{Acknowledgments}

This article was supported by the state grant KEGA 069TUKE4/2017 of the Ministry of Education of the Slovak Republic.

\section{References and Notes}

[1] Vgl. u.a. Haverich, A., Steinhoff, G., Stock, U. et. al. (2000) Gewebezüchtung: (Tissue Engineering) von Her-zklappen, Dtsch. Arztebl., 97(8): A-448 / B-396 / C-358.

[2] Trebuňová, M., Mezencevová, V., Živčák, J. (2017), Biomedical engineering - part of medicine, Acta Simulatio, 3(2), 1-6.

[3] Trebuňová, M., Mezencevová, V., Živčák, J. (2017), Medicine and engineering - connection biology, technology and informatics, Acta Tecnologia, 3(1), 11-14.

[4] Živčák, J., Sidun, J., Dabrowsky, J. R., Hudák, R., (2014), Procesy degradácie v implantológii, 1. vyd. - Prešov: ManaCON - 2014. - 137 s. - ISBN 978-80-89040-41-4.

[5] Fraker, A.C., Fisher, C.A., Griffin, CH.D., (1985) Corrosion and Degradation of Implant Materials. ASTM Committee F-4 on Medical and Surgical Material s and Devices, ASTM International.Lennarz,W. J., Lane, M.D., Encyclopedia of biological chemistry, four-volume set, 1-4 [online] https://cs.wikipedia. org/wiki/Cytokin

[6] Pivodová, V., Franková, J., Ulrichová, J.: (2011) Osteoblast and gingival fibroblast markers in dental implant studies. Biomed. Pap. Med. Fac. Univ. Palacky Olomouc Czech Repub. , 155(2), 109-116.

[7] Reichenberg, E., Redlich, M., Cancemi, P. Zaks, B. (2005) Pro- 
teomic analysis of protein components in periodontal ligament fibroblasts, J Periodontol, 76: 1645-53.

[8] Franková, J., Pivodová, V., Ružička, F. et al.: (2013) Comparing biocompatibility of gingvinal fibroblasts and bacterial strains on a different modified titanium discs. J. Biomed Mater Res A. 101(10):2945-24.

[9] Petkovic, A.B., Matic, S.M., Stamatovic, N.V. et al. (2010) Proinflammatory cytokines (II-1 $\beta$ and TNF- $a$ ) and chemokines (II8 and MIP-1a) as markers of peri-implant tissue condition. Int J Oral Maxillofac Surg, 39:478-485.

[10] Narayanan, A.S., Page, R.C. (1983) Connective Tissues of the Periodontium - a summary of current work. Collagen Rel Res, 3:33-64.

[11] Abe, T., Hara, Y., Abe, Y et al. (1998) Serum or growth factor deprivation induces the expression of alkaline phosphatase in human gingival fibroblasts. J Dent Res, 77:1700-1707.

[12] Chiquet, M., Koch, M., Tannheimer, M. et al. (1996) Regulation of extracellular matrix synthesis by mechanical stress Biochem Cell Biol, 74:737-44.

[13] Borsani, E., Salgarello, S., Mensi, M et al. (2005) Histochemical and immunohistochemical evaluation of gingival collagen and metalloproteinasrs in peri implantitis, Acta Histochem, 107:231-240.

[14] Martinez, E.F., Araujo, V.C. (2004) In vitro immunoexpression of extracellular matrix proteins in dental pulpal and gingival human fibroblasts, Int Endod J, 37:749-755.

[15] Hynes, R.O. (1986) Fibronectins, Sci Am, 254:42-51.

[16] Martinez-Hernandez, A. (1983) The basement membrane in pathology, Lab Invest, 48:656-77.

[17] Lallier, T.E., Spencer, A., Fowler, M.N. (2005) Transcript profiling of periodontal fibroblasts and osteoblasts, J Periodontol, 76:1044-1055.

[18] Fassmann, A. (2006) Kostní tkáňové inženýrství v orofaciální oblasti, Brno: Nucleus HK, 105p. ISBN: 80-86558-82-8.

[19] El-Ghannam, A., Starr, L., Jones, J. et al. (1998) Lamini-5 coating enhances epithelial cell attachment, spreading, and hemidesmosome assembly on Ti-6A1-4V implant material in vitro. J Biomed Mater Res, 41:30-40.

[20] Gordon, J.A.R., Tye, C.E., Sampaio, A.V. et al. (2007) Bone sialoprotein expression enhances osteoblast differentiation and matrix mineralization in vitro, Bone, 41:462-473.

[21] Xu, L., Anderson, A.L., Lu, Q.H. et al. (2007) Role of fibrillar structure of collagenous cerrier in bone sialoprotein-mediated matrix mineralization and osteoblast differentiation. Biomaterials, 28:750-761.

[22] Goto, T., Yoshinari, M., Kobayashi, S. Tanaka, T. (2004) The initial attachment and subsequent behavior of osteoblastic cells and oral epithelial cells on titanium. Bio-Med Mater Eng, 14:537-544.

[23] Diener, A. Nebe, B., Luthen, F. et al. (2005) Control of foca adhesion dynamics by material surface characteristics. Biomaterials, 26:383-392.

[24] Riss, T.L., Moravec, R.A., Niles, A.L., Duellman, S., Benink, H.A., Worzella, T.J., Minor, L., (2016) Cell Viability Assays, Assay Guidance Manual [Internet]. https://www.ncbi.nIm.nih. gov/books/NBK144065/

[25] https://www.biocompare.com/Immunochemicals/7185ELISA/

[26] http://www.sbs.utexas.edu/sanders/Bio347/Lectures/2006/Lecture\%208\%202006.htm 